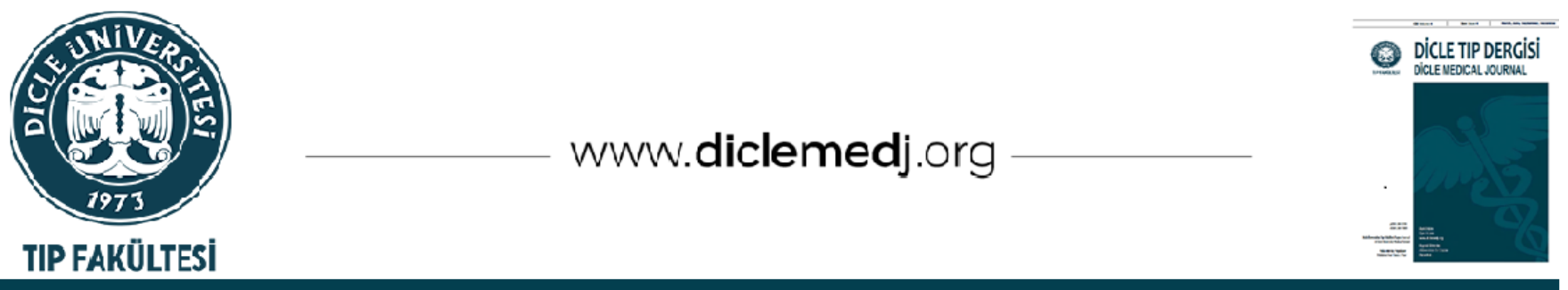

\title{
İntravitreal Bevacizumab ile Tedavi Edilen Prematüre Retinopatili Bebeklerde Risk Faktörlerinin Değerlendirilmesi
}

\author{
Leyla Hazar ${ }^{i}{ }_{1}$, Mine Karahan ${ }^{1}$, Mehmet Emin Dursun ${ }^{D_{1}}$, Sedat Ava ${ }^{1}$, Seyfettin Erdem ${ }^{1}$, \\ Esra Vural ${ }^{i}{ }_{2}$, Uğur Keklikçi ${ }^{i}{ }_{1}$ \\ 1 Dicle Üniversitesi Tıp Fakültesi, Göz Hastalıkları Anabilim Dalı, Diyarbakır, Türkiye
}

2 Kayseri Şehir Hastanesi, Göz Hastalıkları Anabilim Dalı, Kayseri, Türkiye

Geliş: 10.05.2021; Revizyon: 04.08.2021; Kabul Tarihi: 08.08.2021

$\ddot{0} \mathbf{z}$

Amaç: Prematüre retinopatisi (PR) olgularında retinopatinin şiddeti ile anne ve bebekteki risk faktörlerinin ilişkisini analiz etmek

Yöntemler: Haziran 2017- Ekim 2020 yılları arasında Dicle Üniversitesi Tıp Fakültesinde prematüre retinopatisi nedeniyle takip edilen bebeklerin verileri retrospektif olarak değerlendirildi. Prematüre bebeklerin, doğum yaşı, doğum ağırlı̆̆l, takip süresince eşlik eden komorbid hastalıklar, annenin gebelik problemleri kaydedildi. Tedavisiz takip edilenler (grup 1) ve intravitreal bevacizumab tedavisi uygulananlar (grup 2) karşılaștırıldı.

Sonuçlar: Çalışmaya 167 prematüre bebek alındı. Prematüre bebeklerin 99'unda (\%60) tedavi gerektirmeyen PR vardı (grup 1), 68'ine (\%40) intravitreal bevacizumab (grup 2) uygulandı. Grup 2'nin gestasyonel yaşı ve doğum ağırlığı grup 1'den anlamlı olarak düşük iken ( $\mathrm{p}<0.001$ ve $\mathrm{p}<0.001$ ) cinsiyet dağlımları açısından fark yoktu ( $\mathrm{p}=0.387)$. İkizden ikize transfüzyon, Rh uyumsuzluğu, korioamnionit, erken membran rüptürü oranları iki grupta benzer bulundu ( $p>0.05)$. Grup 2'de Respiratuar Distress Sendromu (RDS) anlamlı olarak daha yaygın görüldü ( $\mathrm{p}=0.010)$. Lojistik regresyon analizinde doğum ağırlığı anlamlı bağımsız risk faktörü olarak bulundu ( $\mathrm{p}=0.048 ; \% 95$ GA, 0.993-1.00).

Tartışma: Tedavi gerektiren PR' li bebeklerde düşük doğum ağırlığı bağımsız bir risk faktörüdür. Eşlik eden komorbid durumların etkisini daha iyi ortaya koymak için büyük ölçekli, çok merkezli çalışmalara ihtiyaç vardır.

Anahtar kelimeler: prematüre, retinopati, bevacizumab, solunum sıkıntısı sendromu, düşük doğum ağırlı̆̆

DOI: 10.5798/dicletip.988082

Correspondence / Yazıșma Adresi: Leyla Hazar, Dicle Üniversitesi Tıp Fakültesi, Göz Hastalıkları AD, 21280, Sur/Diyarbakır, Türkiye email: drleylahazar@hotmail.com 


\title{
Evaluation of Risk Factors in Infants with Premature Retinopathy Treated with Intravitreal Bevacizumab
}

\begin{abstract}
Objective: To analyze the relationship between the severity of retinopathy in premature infants and risk factors in the mother and infant.

Methods: The medical records of the infants who were followed up at Dicle University Faculty of Medicine due to retinopathy of premature (ROP) between June 2017 and October 2020 were retrospectively evaluated. Birth age, birth weight, accompanying comorbid diseases during the follow-up period, and pregnancy problems of the mother were recorded. Those who were followed up without treatment (group 1) and those who received intravitreal bevacizumab treatment (group 2) were compared.

Results: One hundred sixty seven premature infants were included in the study. Ninety nine of them (60\%) had ROP that did not require treatment (group 1), 68 (40\%) were administered intravitreal bevacizumab (group 2). While the gestational age and birth weight of group 2 were significantly lower than group 1 ( $p<0.001$ and p $<0.001$ ), no difference was found in terms of gender distributions ( $p=0.387)$. Respiratory Distress Syndrome (RDS) was significantly more common in premature infants who received intravitreal treatment $(p=0.010)$. Birth weight was found to be a significant independent risk factor in logistic regression analysis ( $p=0.048$; 95\% CI, 0.993-1.00). The rates of twin to twin transfusion, Rh incompatibility, chorioamnionitis, and premature rupture of membranes were similar in the two groups $(\mathrm{p}>0.05)$.
\end{abstract}

Discussion: Low birth weight is a significant independent risk factor in infants with retinopathy of prematurity requiring treatment. Large-scale, multi-center studies are needed to better reveal the effect of risk factors.

Keywords: prematurity, retinopathy, bevacizumab, respiratory distress syndrome, low birth weight.

\section{GíRiş}

Prematüre retinopatisi (PR) tedavisiz bırakıldığında körlükle sonuçlanabilen ve tedaviye rağmen şaşıllk, miyopi, ambliyopi gibi morbiditenin görülebildiği önemli bir sağlık sorunudur ${ }^{1}$. Yardımcl üreme tekniklerinin gelişmesi prematüre doğumların artmasına, yoğun bakım koşullarının iyileştirilmesi de bebeklerin yaşama şansının artmasına sebep olmuştur $^{2}$. Anne karnında hipoksik ortamda bulunan bebeğin, doğumda yüksek oksijene maruziyeti ile eritropoietin ve vasküler endotelyal büyüme faktörünün (VEGF) baskılandığı ve retinanın vasküler gelişimini engellediği bilinmektedir (vazoobliteratif faz). Retinal vaskularizasyon bozulduğu için oksijen ihtiyacının karşılanamaması ve hipoksinin etkisiyle retinada VEGF, eritropoietin, IGF-1 gibi mediyatörlerin seviyesinin artması sonucunda neovaskülarizasyon görülür (vazoproliferatif $\mathrm{faz}^{3}$. Bu patolojiye sebep olan, bilinen en önemli risk faktörleri düşük gestasyonel yaş
(GY), düşük doğum ağırlığı (DA) ve oksijen tedavisidir4. TR-ROP çalışma grubu Türkiye'de 34 hafta ve altında doğan veya $1700 \mathrm{~g}$ ve altında doğum ağırlı̆̆ı olan bebeklerin prematüre retinopatisi açısından taranmasını uygun görmüştür 5 .

Prematüriteyle birlikte, preeklampsi, ikizden ikize transfüzyon, Rh uyumsuzluğu, neonatal sepsis, nekrotizan enterokolit, intrakraniyal hemoraji gibi antenatal, postnatal birçok risk faktörünün prematüre retinopatisi ve şiddeti ile ilişkili bulunduğunu bildiren çalışmalar mevcuttur ${ }^{5-8}$.

Prematüre retinopatisi açısından tarama protokollerinin ülkelerin gelişmişlik seviyesine göre değişebildiği tespitiyle birlikte risk faktörlerinin de değişken olabileceğini söylemek mümkündür ${ }^{5}$. Bu çalışmada amacımız PR tanısıyla takip ettiğimiz infantların demografik özelliklerini ve eşlik eden komorbid 
hastalıklarını analiz etmek ve bunların PR şiddeti ile ilişkisini değerlendirmektir.

\section{YÖNTEMLER}

Haziran 2017- Ekim 2020 yılları arasında Dicle Üniversitesi Tıp Fakültesinde, prematüre retinopatisi nedeniyle takip edilen bebeklerin kartları retrospektif olarak değerlendirildi. Çalışma Helsinki Deklarasyonuna uygun yürütüldü ve yerel etik kurul onayı (Tarih: 04/02/2021, Karar no: 123) alındı.

Düzenli takibi olan bebekler çalışmaya alındı. Prematüre bebeklerin, gestasyonel yașı, doğum ağırlığı, takip süresince eşlik eden komorbid hastalıklar, annenin gebelik problemleri kaydedildi.

İlk ROP muayenesi, GY <27 hafta olan bebekler postmenstrüel yaşın 31 . haftasında ve $G Y \geq 27$ hafta olanların dört hafta sonra yapıldı. Bebekler muayene edilmeden önce pupilla dilatasyonu 10 dakika arayla \% 2,5 fenilefrin (Mydfrin, Alcon, ABD) ve \%0,5 tropikamid (Tropamide, Bilim İlaç, Türkiye) $3 \mathrm{kez}$ uygulanarak sağlandı. İndirekt oftalmoskop, 28 dioptri lens ve skleral depresör kullanılarak fundus muayenesi yapilan bebekler, Uluslararası ROP Sinıflandırma Komitesi'nin (ICROP, 2005) standardına göre sinıflandırıldı ${ }^{9}$. Prematüre Retinopatisi Erken Tedavi çalışma grubu tarafından belirlenen kriterlere göre tedavi planland ${ }^{10}$. Buna göre; (a) plus hastalığa eşlik eden, zon 2'de evre 2 veya evre 3 PR (b) plus hastalığa eşlik eden zon 1 'de evre 1 veya evre 2 PR (c) zon 1'de evre 3 PR (d) agresif posterior PR (APROP) olanlara 0,675 mg / $0,025 \mathrm{ml}$ dozda intravitreal bevacizumab uygulandı. Enjeksiyon ameliyathanede, steril koşullar altında yapıldı. Göz muayenelerine retina damarlanması tamamlanana kadar devam edildi. Tedavisiz takip edilenler (grup 1) ve intravitreal bevacizumab ile tedavi uygulananlar (grup 2) risk faktörleri açısından karşılaştırıldı.

\section{İstatistiksel Analiz}

İstatistiksel analizler IBM SPSS (Windows için Sosyal Bilimler için İstatistik Paketi, Sürüm 21.0, Armonk, NY, IBM Corp.) paket programı ile sağlandı. Fisher Exact (örneklem sayısının düşük olduğu durumlarda) ve Ki-kare testi, kategorik değişkenler arasındaki oranlar veya ilişkiler arasındaki farkları belirlemek için kullanıldı. Paremetrelere ait sayısal değerlerin belirli kategorik gruplar arası dağılımını karşılaştırmak için Anova T Test, Mann Whitney U Test veya Kruskal-Wallis H kullanıldı. Tedavi gerektiren ROP varlığıyla ilişkili bağımsız risk faktörlerini tahmin etmek için lojistik regresyon analizi yapıldı. Her olası risk faktörü için olasılık oranı (OR) ve \%95 güven aralıkları hesaplandı. Tüm olgular için istatistiksel anlamlılık $\mathrm{p}<0.05$ olarak belirlendi.

\section{SONUÇLAR}

Yüz altmış yedi prematüre bebeğin 99'u takip ile regrese oldu (grup 1), 68'ine intravitreal bevacizumab (grup 2) uygulandı. Grup 2'nin yaş ortalaması ve doğum ağırlığı grup 1'den anlamlı olarak düşük iken $(p<0.001$ ve $p<0.001)$ cinsiyet dağılımları açısından fark bulunamadı ( $\mathrm{p}=0.387$ ) (Tablo 1). Grup 2' de respiratuar distress sendromu (RDS) anlamlı olarak daha yaygın görüldü $(\mathrm{p}=0.010)$. Çoklu doğum açısından iki grup arasında fark bulunamadı $(\mathrm{p}=0.577)$. İkizden ikize transfüzyon, $\mathrm{Rh}$ uyumsuzluğu ve korioamnionit, annede diyabet, erken membran rüptürü (EMR) oranları iki grupta benzer bulundu ( $p>0.05)$ (Tablo 2). Lojistik regresyon analizi sonuçları Tablo 3'te verildi. Buna göre düşük doğum ağırlığı bağımsız risk faktörü olarak bulundu ( $p=0.048$; \%95 GA: 0.99-1.00). 
Tablo I: Prematüre bebeklerin doğum yaşı, doğum ağırlığı ve cinsiyet dağılımı

\begin{tabular}{|c|c|c|c|}
\hline & $\begin{array}{l}\text { Grup } 1(\mathrm{n}=99) \\
(\text { Mean } \pm \text { SD) or }(\mathrm{n})\end{array}$ & $\begin{array}{l}\text { Grup } 2 \quad(n=68) \\
(\text { Mean } \pm \\
(n \%)\end{array}$ & P değeri \\
\hline $\begin{array}{l}\text { Doğum yaşı } \\
\text { (hafta) }\end{array}$ & $26.69 \pm 2.19$ & $24.48 \pm 1.55$ & $* \mathbf{p}<\mathbf{0 . 0 0 1}$ \\
\hline $\begin{array}{l}\text { Doğum ağırlığ } \\
\text { (gram) }\end{array}$ & $1006.61 \pm 277.41$ & $769.77 \pm 176.78$ & ${ }^{*} \mathbf{p}<0.001$ \\
\hline $\begin{array}{l}\text { Cinsiyet } \\
\text { Kı//erkek }\end{array}$ & $56 / 43$ & $35 / 33$ & ** 0.387 \\
\hline
\end{tabular}

*Mann Whitney U Test ${ }^{* *}$ Pearson Chi-Squared Test, $p<0.05$ istatistiksel olarak anlaml

Tablo II: Prematür bebekte ve annede görülen komorbid durumların iki grup arasındaki dağılımı

\begin{tabular}{|c|c|c|c|}
\hline & $\begin{array}{l}\text { Grup } 1 \\
\text { n, \% }\end{array}$ & $\begin{array}{l}\text { Grup } 2 \\
\text { n, \% }\end{array}$ & P değeri \\
\hline Erken Membran Rüptürü & $4(\% 4)$ & $0(\% 0)$ & $* * 0.146$ \\
\hline Ikizden_Ikize_Transfuzyon & $6(\% 6)$ & $2(\% 3)$ & $* * 0.295$ \\
\hline Rh_Uygunsuzlugu & $1(\% 1)$ & $1(\% 1)$ & $* * 1$ \\
\hline Koryoamnionit & $0(\% 0)$ & $2(\% 3)$ & $* * 0.164$ \\
\hline Oligohidroamnios & $6(\% 6)$ & $8(\% 12)$ & $* 0.306$ \\
\hline Annede Diyabet & $0(\% 0)$ & $2(\% 3)$ & $* * 0.164$ \\
\hline Eklampsi & $0(\% 0)$ & $2(\% 3)$ & $* * 0.164$ \\
\hline Preeklampsi & $6(\% 6)$ & 1(\%1) & $* * 0.243$ \\
\hline RDS & $18(\% 18)$ & $\begin{array}{l}26 \\
(\% 38)\end{array}$ & $* 0.010$ \\
\hline Çoklu gebelik & $10(\% 10)$ & $8(\% 12)$ & $* * 0.577$ \\
\hline
\end{tabular}

*Pearson Chi-Squared Test, **Fisher exact test, $p<0.05$ istatistiksel olarak anlaml
Tablo III: Tedavi gerektiren PR için bağımsız risk faktörleri

\begin{tabular}{|c|c|c|c|c|}
\hline \multirow[b]{2}{*}{ Doğum yaşı } & \multirow{2}{*}{\begin{tabular}{|l}
$\begin{array}{l}\text { Odds } \\
\text { ratio }\end{array}$ \\
0.99
\end{tabular}} & \multirow{2}{*}{\begin{tabular}{|l} 
P değeri \\
0.956
\end{tabular}} & \multicolumn{2}{|c|}{$\begin{array}{l}95 \% \mathrm{GA} \\
\text { Alt limit Üst limit }\end{array}$} \\
\hline & & & 0.716 & 1.372 \\
\hline Doğum ağırlığı & 0.99 & 0.048 & 0.993 & 1.00 \\
\hline RDS & 0.74 & 0.589 & 0.260 & 2.148 \\
\hline
\end{tabular}

Lojistik regresyon (binary) analizi kullanıld. $p<0.05$ istatistiksel olarak anlamlı. GA: Güven aralı̆̆ı

\section{TARTIŞMA}

Çalışmamızda, tedavi uygulanan PR grubunda doğum ağırlığı ve doğum haftası anlamlı olarak düşüktü, ayrıca tedavi gerektiren PR' li infantlarda RDS anlamlı olarak daha yaygın saptandl.

Prematüre retinopatisi ve şiddeti ile ilişkili maternal risk faktörünü analiz eden bazı çalışmalarda annede hipertansif hastalık, annede diyabet, EMR, sigara kullanımı, koryoamnionit, annede demir eksikliği anemisi risk faktörü olarak bulunmuștur ${ }^{11-14}$. Annede preeklampsi ve eklampsiyi risk faktörü olarak değerlendiren çalışmalar olası mekanizmanın VEGF'in bir antagonisti olan soluable fms like tirozin kinaz-1'in yüksek seviyeleri ile düşük seviyelerde PIGF'in olduğunu savunmuşlardır ${ }^{11}$. Bazı büyük ölçekli çalışmalar ise, preeklampsinin PR ile ilişkili olmadığını bildirmiştir ${ }^{15}$. Bizim çalışmamızda da preeklampsi ve eklampsi açısından gruplar arasında fark saptanmadl.

Hayvan çalışmaları, sistemik inflamasyonun yeni doğan hayvanlarda retinal anjiyogenezi bozduğunu göstermiştir ${ }^{16}$. Koryoamnionit gibi maternal ve plasental enfeksiyon / enflamasyonu takiben kan dolaşımındaki bozukluk ve oksijen satürasyonunun 
dalgalanması retina perfüzyonunu etkileyebilir ve artmış retina hasarına neden olabilir ${ }^{17}$. Ayrıca koryoamnionitin erken doğum için bir etiyolojik faktör olduğu ve PR patogenezi üzerindeki etkisine bu yönüyle bakmak gerektiği vurgulanmıştır ${ }^{18}$. Yapılan bir metaanalizde, koryoamniyonitin tek değișkenli analizlerle PR ile önemli ölçüde ilişkili olduğunu, ancak çok değişkenli bir analizde ilişki bulunamadığı belirtilmiştir ${ }^{19}$.

Bununla birlikte erken doğumun bir sebebi olan EMR'nin PR ile ilişsisini analiz eden ve çelişkili sonuçlar bildiren yayınlar mevcuttur20-22. Türkiye'den tek merkezli bir çalışmada, uzamış EMR'nin tip 1 PR açısından bağımsız risk faktörü olduğu, ancak bașka bir çalışmada EMR' nin PR ye karşs koruyucu bir etkiye sahip olduğu bildirilmiștir ${ }^{20,21}$. Ünsal ve ark.' nın yaptığ çalışmada EMR gelişenlerin \%83,3'ünde ROP geliştiği bildirilmiştir ${ }^{22}$. Kavurt ve ark.'nın çalışma sonuçlarına göre korioamnionit, EMR ve preeklampsi gibi maternal risk faktörlerinin \%34,7 oranında ROP gelişimini arttırdığ gösterilmiştir ${ }^{11}$. Bizim çalışmamızda koryoamnionit ve EMR her iki grupta benzer sıklıkta görüldü.

Ünsal ve ark Tip 1 PR görülen bebeklerin annelerinde kan şekerini anlamlı olarak daha yüksek bulmuşken gestasyonel diyabetin tedavi gerektiren PR ile ilişkisinin bulunmadığını bildirmişler ${ }^{22}$. Bizim çalışmamızda da PR' li infantlarda annede diyabet varlı̆̆ gruplar arasında fark olmadığı görüldü.

Çoklu doğumlarda erken doğum riski olduğu bilinmektedir. Bebek sayısı arttıkça bu risk artmaktadır ${ }^{23,24}$. Tek başına çoklu doğumu PR varlığı ve şiddeti ile ilişkili bulan çalışma olduğu gibi tekli doğum ve çoklu doğum arasında fark bildirmeyen birçok çalışma da mevcuttur ${ }^{25}$. Bizim çalışmamızda da tekli gebelik ve çoklu gebeliğin tedavi alan PR ile ilişkisi bulunamadı.

Prematüre retinopatisi gelişimi ve PR şiddeti ile infanta ait bildirilen risk faktörleri; oksijen tedavi süresi, nekrotizan enterokolit, intrakranial hemoraji, RDS, sepsis, bronkopulmoner displazi, ikizden ikize transfüzyon, bebeğe kan transfüzyonu, trobositopenidir $5,8,26-27$. PR ile ilişsili altta yatan patofizyolojinin yetersiz ve/veya bozulmuş oksijenizasyon ve inflamasyona bağlı VEGF ve IGF 1 artışı olduğu belirtilmiştir³.

Respiratuar distress sendromlu bebeklerde hipoksiye bağlı olarak mekanik ventilasyon ve oksijen tedavisi gereksinimi olabilir, bunların ikisi de PR insidansında artış ile ilişkilendirilebilinir. Yapılan çok merkezli bir çalışmada düşük doğum ağırlığı ve RDS'nin agresif posterior PR gelişiminde anlamlı risk faktörü olduğu görülmüştür ${ }^{7}$. Bizim çalışmamızda tedavi gerektiren grup ile takiple regrese olan grup arasında RDS sıklı̆̆ a açısından anlamlı fark bulundu. Ancak lojistik regresyon analizinde RDS bağımsız risk faktörü olarak bulunmadl.

Kan transfüzyonları, anemiyi tedavi etmek için kullanılan rekombinant EPO PR gelişimi açısından risk faktörleri olarak belirtilmiştir. Hem böbrekte hem de retinada oksijen tarafından düzenlenen EPO, önemli bir proanjiyojenik faktördür ve bir fare modelinde retinal vasküler stabilite ile ilişkilendirildiğinden, düşük EPO' dan kaynaklanan aneminin, PR gelişimi ile iliş̧ili olabileceği bildirilmiştir ${ }^{3,8}$. Ayrıca, transfüzyona bağlı olarak artmış demir yükünün oksidatif hasarı hızlandırarak PR' ye yatkınlık yaratabileceği bildirilmiştir ${ }^{8}$. Bununla birlikte TR ROP çalışma grubu, eșik hemoglobin değeri sağlayarak yapılan sınırlı transfüzyonun PR prevalansında azalmaya neden olabileceğini bildirmiştir ${ }^{5}$. Çalışmamızda ikizden ikize transfüzyon, bebeğe kan transfüzyonu ve $R h$ uyumsuzluğu açısından gruplar arasında fark olmadığı tespit edildi.

Prematüre retinopatisi gelişimi ve şiddeti ile ilgili bilinen en önemli risk faktörleri hala GY ve 
DA' nın düşüklügüdür. Ancak büyük prematürelerde de tedavi gerektiren PR görülebildiği bilinmektedir, bu nedenle tüm prematürelerin dikkatle taranması gerektiği vurgulanmıştır ${ }^{28,29}$.

Çalışmamıza PR bulgusu olmayan prematüreler ve GY 32 haftadan büyükler alınmadı, kontrol grubu olarak tedavi gerektirmeyen PR' li infantlar alındı bu yönüyle diğer çalışmalardan ayrılmaktadır. Çalışmamızın ana kısıtlılı̆̆ı retrospektif olmasıdır. Annelerin sigara kullanımı öyküsüne tam olarak ulaşamamayı da bir kısıtlılık olarak görüyoruz.

Çalışmamız, tedavi gerektiren PR' li bebeklerde düşük doğum ağırlığının bağımsız bir risk faktörü olduğunu ortaya koymuştur. Prematüre retinopatisi multifaktöriyel bir hastalıktır ve etnisite, anne ve bebeğin immun sistemi, beslenme, yoğun bakım koşulları gibi birçok durumun PR şiddeti ile ilişkisinin farklı popülasyonlarda ve geniş ölçekli çalışmalarla analiz edilmesi gerektiğini düşünmekteyiz.

Etik Kurul Kararı: Çalıșma Helsinki Deklarasyonuna uygun yürütüldü ve yerel etik kurul onayı (Tarih: 04/02/2021,Karar no:123) alındı.

Çıkar Çatışması Beyanı: Çıkar çatışması bulunmamaktadır.

Finansal Destek: Bu çalışma her hangi bir fon tarafından desteklenmemiştir.

Declaration of Conflicting Interests: The author declare that she has no conflict of interest.

Financial Disclosure: No financial support was received.

\section{KAYNAKLAR}

1. Goktas A, Sener EC, Sanac AS. An assessment of ocular morbidities of children born prematurely in early childhood. J Pediatr Ophthalmol Strabismus. 2012; 49: 236-41.
2. Gilbert C, Fielder A, Gordillo L, et al. Characteristics of infants with severe retinopathy of prematurity in countries with low, moderate, and high levels of development: implications for screening programs. Pediatrics. 2005; 115: e51825.

3. Akkoyun, İ. Prematüre Retinopatisinin Patofizyolojisi. Turk J Ophthalmol, 2012; 42: 63-7.

4. Martin RJ, Fanaroff AA, Walsh MC, Fanaroff and Martin's neonatal perinatal medicine: diseases of the fetus and infant. Philadelphia: Elsevier Saunders, 2015: 1767-4.

5. Bas AY, Demirel N, Koc E, et al. Incidence, risk factors and severity of retinopathy of prematurity in Turkey (TR-ROP study): a prospective, multicentre study in 69 neonatal intensive care units. Br J Ophthalmol. 2018; 102: 1711-16.

6. Wikstrand $\mathrm{MH}$, Hard AL, Niklasson A, et al. Maternal and neonatal factors associated with poor early weight gain and later retinopathy of prematurity. Acta Paediatr. 2011; 100:1528-33.

7. Dwivedi A, Dwivedi D, Lakhtakia S, et al. Prevalence, risk factors and pattern of severe retinopathy of prematurity in eastern Madhya Pradesh. Indian J Ophthalmol. 2019; 67: 819-23.

8. Zhu Z, Hua X, Yu Y, et al. Effect of red blood cell transfusion on the development of retinopathy of prematurity: A systematic review and metaanalysis. PLoS One. 2020; 15: e0234266.

9. International Committee for the Classification of Retinopathy of Prematurity. The International Classification of Retinopathy of Prematurity revisited. Arch Ophthalmol 2005; 123: 991-9.

10. Early Treatment for Retinopathy of Prematurity Cooperative Group, Results of the early treatment for retinopathy of prematurity randomized trial: revised indications for the treatment of retinopathy of prematurity, Arch Ophthalmol. 2003; 121: 168496.

11. Kavurt S, Yücel H, Hekimoğlu E, et al. Prematüre retinopatisi gelişen olgularda risk faktörlerinin değerlendirilmesi. Çocuk Sağlığı ve Hastalıkları Dergisi 2012; 55: 125-31.

12. Tunay ZÖ, Özdemir Ö, Acar DE, et al. Maternal diabetes as an independent risk factor for 
retinopathy of prematurity in infants with birth weight of $1500 \mathrm{~g}$ or more. Am J of Ophthalmol 2016; 168: 201- 6 .

13. Dai AI, Demiryürek S, Aksoy SN, et al. Maternal iron deficiency anemia as a risk factor for the development of retinopathy of prematurity. Pediatric Neurology 2015; 53: 146-50.

14. Zhu TT, Zhang L, Zhao FY, et al. Association of maternal hypertensive disorders with retinopathy of prematurity: A systematic review and metaanalysis. PLoS ONE 2017; 12: e0175374.

15. Yu XD, Branch DW, Karumanchi SA, et al. Preeclampsia and retinopathy of prematurity in preterm births. Pediatrics. 2012; 130: e101-7.

16. Hong HK, Lee HJ, Ko JH, et al. Neonatal systemic inflammation in rats alters retinal vessel development and simulates pathologic features of retinopathy of prematurity. J Neuroinflammation. 2014; 11: 1-10.

17. Woo SJ, Park KH, Jung HJ, et al. Effects of maternal and placental inflammation on retinopathy of prematurity. Graefes Arch Clin Exp Ophthalmol. 2012; 250: 915-23.

18. Villamor-Martinez E, Cavallaro G, Raffaeli G, et al. Chorioamnionitis as a risk factor for retinopathy of prematurity: An updated systematic review and meta-analysis. PloS one, 2018;13: e0205838.

19. Mitra S, Aune D, Speer CP, et al. Chorioamnionitis as a risk factor for retinopathy of prematurity: a systematic review and meta-analysis. Neonatology. 2014; 105:189-99.

20. Ozdemır R, Sarı FN, Tunay ZO, et al. The association between respiratory tract Ureaplasma urealyticum colonization and severe retinopathy of prematurity in preterm infants $\leq 1250 \mathrm{~g}$. Eye (Lond). 2012; 26: 992-6.

21. Lynch AM, Wagner BD, Hodges JK, et al. The relationship of the subtypes of preterm birth with retinopathy of prematurity. Am J Obstet Gynecol. 2017; 217: 354-e1.

22. Ünsal AİA, Sezer SD, Güler D, et al. Maternal faktörlerin Prematür Retinopatisi gelişimindeki olası rolü. Pam Tıp Der, 2019; 12: 569-75.

23. Sood V, Chellani H, Arya S, et al. Changing spectrum of retinopathy of prematurity (ROP) and variations among siblings of multiple gestation. Indian J Pediatr. 2012; 79:905-10.

24. Conde-Agudelo A, Romero R, Hassan SS, et al. Transvaginal sonographic cervical length for the prediction of spontaneous preterm birth in twin pregnancies: a systematic review and metaanalysis. Am J Obstet Gynecol 2010; 203: 128 e1e12.

25. Şekeroğlu MA, Hekimoğlu E, Çelik Ü, et al. Üçüz Bebeklerde Prematüre Retinopatisi. Turk J Ophthalmol, 2016; 46: 114-7.

26. Hellstro"m A, Smith LE, Dammann 0 . Retinopathy of prematurity. Lancet. 2013; 382: 1445-57.

27. Park SH, Yum HR, Kim S, et al. Retinopathy of prematurity in Korean infants with birthweight greater than $1500 \mathrm{~g}$. Br J Ophthalmol. 2016; 100: 834-8.

28. Oyur G, Hazar L, Vural E, et al. Evaluation of Retinopathy Severity According to the Premature Stage in Premature Retinopathy. Van Med J, 2019; 27: 139-43.

29. Sukgen EA, Koçluk Y, Mert K. Büyük Prematüre Bebekler Ağır Retinopati ile Karşı Karşıya. Ret-Vit 2018; 27: 43-7. 